\title{
English Translation of Chinese Tea Terminology from the Perspective of Translation Ethics
}

\author{
Peiying Guo, Mei Yang \\ School of Arts and Sciences, Shaanxi University of Science and Technology (SUST), Xi'an, China \\ Email: 466160439@qq.com, 1264707661@qq.com
}

How to cite this paper: Guo, P. Y., \& Yang, M. (2019). English Translation of Chinese Tea Terminology from the Perspective of Translation Ethics. Open Journal of Modern Linguistics, 9, 179-190. https://doi.org/10.4236/ojml.2019.93017

Received: May 7, 2019

Accepted: June 1, 2019

Published: June 4, 2019

Copyright ( 2019 by author(s) and Scientific Research Publishing Inc. This work is licensed under the Creative Commons Attribution International License (CC BY 4.0).

http://creativecommons.org/licenses/by/4.0/

\section{(c) (i) Open Access}

\begin{abstract}
The English translation of Chinese tea terminology not only facilitates tea export but also functions as a bridge for the international communication of tea culture. However, the lack of translation norms for tea terminology in China leads to various translation problems, resulting in the failure of international tea communication. Translation, as an important means of intercultural communication, requires the constraints of ethics. Based on five models of Chesterman's translation ethics, in combination with the different translation tasks, this paper divided tea terminology into five corresponding categories and analyzed how Chesterman's five translation ethics were applied in tea terminology translation. The results show that Chesterman's translation ethics is applicable to improving the quality of tea terminology translation.
\end{abstract}

\section{Keywords}

Tea Terminology Translation, Chesterman's Translation Ethics, Classification of Tea Terminology

\section{Introduction}

Chinese tea has become popular in western countries since it was introduced to Britain in the 17th century. With globalization and the increasing demand of tea trade, more and more tea products have been exported to different countries in the world. A large quantity of tea exports not only increase China's economic trade, but also facilitate the spread of Chinese culture, during which the accurate translation of tea terminology plays a key role.

However, mistranslations of tea terminology are frequently found in tea product description or sales promotion advertising. Apart from some grammar 
mistakes, most of the mistranslation is caused either by the translator's failure of understanding the source text, or by the translator's unawareness of cultural differences and of translation service. As a result, the Chinese tea named “大红袍” has been translated in various ways, such as "Dahongpao Tea", "Big Hongpao Tea", "Clovershrub Tea" and "Red Robe Tea", which may mislead customers to mistake them for different types of tea; “六安瓜片(Lu’an Melon Seeds Tea)” is transliterated as "Lu An Gua Pian", which does not make any sense to foreign customers. In effect, “瓜片(Melon Seeds)” means that the tea leaves are shaped like melon seeds. Therefore, if the tea translation only adopts transliteration, it may not only lose the connotation of the tea, but also make the reader unable to understand. In view of these problems, it is of great significance to explore effective strategies for tea terminology translation.

In recent years, the study of translation strategies of tea terminology has aroused great interest of domestic scholars. The latest researches mainly focus on the solutions to the problems in tea terminology translation, and translation methods under the guidance of translation theories. As to the translation problems such as translation errors, transliteration only, multi-translation of one tea and lack of unified translation standards etc., different scholars offered different suggestions from different aspects. Xu Xiaosong (2016) analyzed the problems in current tea terminology translation and put forward some solutions to the problems, such as using translation methods flexibly, learning tea culture background actively and paying attention to consumers' understanding of the translation. By analyzing the characteristics of tea terminology, Ye He (2017) suggested literal translation, free translation and amplification. Besides, Deng Fang (2018) emphasized the importance of translators' knowledge of tea culture in translation and target-reader centered translation strategy.

Furthermore, some scholars studied translation methods based on translation theories. From the aspect of skopos theory, Li Weili (2016) discussed the translation problems and countermeasures of Chinese tea terminology in order to facilitate the spread of Chinese traditional tea culture. Heng Qingzhi (2017) applied the theory of discourse analysis to the tea terminology translation and discussed how to make the translation more concisely and effectively. Moreover, Liang Tianzhu (2018) offered solutions to the problems existing in tea terminology translation from the perspective of applied linguistics.

Different from the above translation theories, translation ethics emphasizes ethics, norms and values, which play a significant guiding role in the translation of tea terminology. Therefore, in this paper, we explored the translation strategies of tea terminology from the perspective of Chesterman's translation ethics. First, Chesterman's five models of translation ethics were reviewed and the internal characteristics and external constraints of tea terminology were analyzed. Then the application of Chesterman's five models of translation ethics in five different types of terminology was explained, aiming to find the influence of the five models on tea terminology translation. The researching result will provide reference in the improvement of tea terminology translation quality. 


\section{Chesterman's Translation Ethics}

"Translation ethics" was first proposed by the French translation theorist Antoine Berman in 1984. Since then, the research on translation ethics has been paid close attention. In contemporary western translation academic field, the more in-depth and comprehensive discussion of ethical issues is Chesterman, Pym and Venuti, who have expounded their understanding of ethical issues in translation from different perspectives (Peng, 2013), of which Chesterman's translation ethics is the most comprehensive and influential one ( $\mathrm{Zhu}, 2009)$.

\subsection{Five Models of Chesterman's Translation Ethics}

In 2001, Chesterman put forward five current ethical models in the paper "Proposal for a Hieronymic Oath", namely, the ethics of representation, the ethics of service, the ethics of communication, the norm-based ethics, and the ethics of commitment. Among them, the first four ethics were put forward by Chesterman on the basis of the existing translation theories in the west, and the last one was his own observation and summary.

1) Ethics of Representation

By ethics of representation, it means that the meaning of the original text should be conveyed without adding, omitting or changing any information in the process of translation (Chesterman, 2001). The ethics of representation lays stress on "faithfulness to the original text" and advocates to maximize represent the language characteristics, writing intentions and cultural connotations of the original text. Representation ethics, like "faithfulness" in translation criteria, requires translators not to deviate from the original text in order to achieve the basic restoration of the original text.

\section{2) Ethics of Service}

Chesterman's ethics of service model focuses on commercial service translation, requiring translators to provide services (translated text) that ultimately meet the needs of the clients (readers) for achieving the goal agreed between the client and the translator ( $\mathrm{Hu}, 2012)$. This ethics focuses on a translator's responsibility for target readers. It requires the translator to adjust or interpret the original text to satisfy the customer on the basis of being faithful to the original text. In other words, the translator must not only show respect to the original author and be faithful to the source text, but also satisfy the target readers' need. Compared with the ethics of representation which embodies the translation principle of "faithfulness", the ethics of service lay stress on the translation principle of "expressiveness" or even "elegance" (Chen, 2010).

\section{3) Ethics of Communication}

As for the ethics of communication, Chesterman believes that it is not the focus to reproduce the original text or to serve the needs of customers, but to communicate with others (Chesterman, 2001). Pym (2012) also proposed that translators work mainly at the intersection of two or more cultures, rather than in one culture. So, it can be known that translation is intercultural communica- 
tion. Therefore, a translator who upholds the principle of ethics of communication shoulders the heavy responsibility of not only accurately transmitting the original information, but also building a bridge for cultural communication. Based on this requirement, the translator should consider what translation method to use to interpret the original text and whether the translation achieves the effect of communication between the source language and the target language, thus better completing the translator cross-language and cross-cultural communication roles.

\section{4) Norm-Based Ethics}

The word "norm" generally refers to the behavior standards established by a certain group. By norm-based translation ethics, "norm" means that translation should meet the expectations of the target language readers, in line with the social ethics and cultural norms of the time, only then can the translation be naturally accepted by the target readers and the target culture. Therefore, if the ethics of representation is regarded as being equivalent to the "foreignization" translation strategy, the norm-based ethics is equivalent to the "domestication" translation strategy. As mentioned above, translators with norm-based ethics should decide what translation strategies to adopt according to the known or expected expectations of target language readers before starting translation. Therefore, the norm-based ethics, to some extent, affects the establishment of translator's overall translation principles.

\section{5) Ethics of Commitment}

In addition to the previous four ethics models, Chesterman himself proposed another model-ethics of commitment. He takes "commitment" to be the glue that binds practitioners to the values of the practice. It is thus also a virtue, encouraging translator to pursue excellence and become a good translator (Chesterman, 2001). In addition, the ethics of commitment is closely related to the professionalization of translation. Translation as a profession has its own professional ethics. Chesterman proposed that translators should follow nine professional ethical principles, which include commitment, loyalty to the profession, understanding, truth, clarity, trustworthiness, truthfulness, justice and striving for excellence (Chesterman, 2001). These professional ethics emphasize that translators must actively fulfill their obligations and strive to be an ethical and responsible translator.

From the above, the representation ethics attaches importance to whether the translator is faithful to the original text or the original author's intention; service ethics emphasizes the importance of the translator's service to customers in translation; the ethics of communication focuses on whether the translator can promote the communication between the source culture and the target culture; norm-based ethics emphasizes that translators should pay attention to the expectations of the target readers and the target culture; and the ethics of commitment regulates the translator's behavior from a professional perspective ( $\mathrm{Li}$, 2019). Chesterman's five translation ethics models provide a new direction for 
the study of translation ethics, broaden the scholars' understanding of "faithfulness", and have important guiding significance for translation activities (Luo, 2014).

\subsection{The Relationship between Chesterman's Five Models with Tea Terminology Translation}

With thousand years of development, tea planting, tea processing, tea tasting, tea ceremony and other cultural contents give rise to specialized words or expressions related to Chinese tea, these lexical words are called tea terminology. Chinese tea terminology has its own characteristics. Some tea terms are named simply after its color, shape, origins while some are heavily culture-loaded.

For the tea terminology named according to the color, shape or origins of tea has single meaning and does not contain deep cultural information. Thus the translation of such tea terminology should be faithful to the original text and preserve the cultural characteristics of tea terminology from the perspective of representation ethics.

With profound culture connotation, culture-loaded tea terms are the biggest challenge for translators. To such terminology, through understanding of the original meaning is not enough. According to communication ethics, translators, as regulators between different cultures, should try to find appropriate way to convey its culture connotation in target language. For example, free translation or adding annotations for translation, may be adopted.

In addition, there is another kind of terms which exist in both Chinese and Western culture but mean quite differently. For example, "Dragon" is a symbol of dignity and power in China, but in the West is a symbol of evil and disaster. Failing to clarify the differences will lead to ambiguity. Therefore, the ethics of commitment should be applied to regulate the translators' behavior from a professional perspective.

The characteristics mentioned above are the intrinsic factors of tea terminology. As a qualified translator, one needs to consider not only the intrinsic characteristics of tea terminology but also the external constraints of them, such as the language levels of readers who used tea terminology and the existing influence of tea terminology in the target country.

Therefore, there are some tea terms used by readers of different language levels. According to service ethics, translators should try to provide translations that ultimately meet the needs of the client. Thus when translating such terms, translators were suggested to provide more targeted translations according to readers' different language levels.

Furthermore, some other tea terms have been widely accepted by Westerners. When translating such tea terminology from the perspective of norm-based ethics, the translator should fully respect the choice of the target text by the target readers and try to make the target text conform to the expectations of the target readers.

The previous analysis shows that the five models of Chesterman's translation 
ethics can be used to guide tea terminology translation. In order to provide more accurate and standardized translation, translators need to consider both the intrinsic characteristics and the external constraints of tea terminology when translating them. Therefore, according to different translation tasks, a classified translation approach is suggested in this paper. That is, Chinese tea terminology can be divided into five different categories based on the translators' distinction between different translation tasks. One of the five models is selected to guide the translation accordingly.

\section{English Translation of Tea Terminology Based on Translation Ethics}

Tea terminology is not only culturally loaded, but also carries practical information. Inappropriate translation will not only mislead foreign customers' purchase of Chinese tea, but also affect the international spread of tea culture. Therefore, in order to improve the translation quality, the authors divide tea terminology into five different categories based on the distinction between different translation tasks, namely, tea terminology named according to tea affiliated characteristics, tea terminology with specific cultural connotation, tea terminology with different meanings in Chinese and Western Culture, tea terminology used for different levels of target readers and tea terminology widely accepted in the west, and then analyze how Chesterman's five translation ethics were applied in tea terminology translation.

\subsection{Tea Terminology Named According to Tea Affiliated Characteristics}

Many Chinese tea terms are named according to the shape and color, mountain name, aroma, picking season, place of origin and other affiliated characteristics of tea, so that these tea terms do not contain cultural information. For the translation of such terminology, if the translator follows the ethics of representation, translating the tea terminology with strategies of literal translation and transliteration, it will not only make the reader easy to understand, but also maintain the essence of the original work. Examples of translation of tea terminology named after its affiliated characteristics under the guidance of representation ethics are as follows.

In Table 1, "Green Tea" and "Yellow Tea" are named according to the color of tea or its soup; "Rose Tea" and "Purple Bamboo Shoot Tea" are named after their shape or color; "Pu'er Tea" is named for its origin in Pu'er city, Yunnan Province; "Pre-Grain Rain Tea" is named after its picking season, which refers to the tea picked before the grain rain season; and "Huangshan Maofeng Tea" is named for its fresh leaves picked from the peak of Huangshan Mountain. For such simple and clear tea terminology with no hidden meaning, the translator is suggested to adopt the strategies of literal translation and transliteration, which is not only faithful to the original text, but also represents the language style and characteristics of the original tea terminology. 
Table 1. Translation of tea terminology under the guidance of representation ethics.

\begin{tabular}{cc}
\hline $\begin{array}{c}\text { Tea terminology named according to } \\
\text { tea affiliated characteristics }\end{array}$ & Translation guided by representation ethics \\
\hline 绿茶 & Green Tea \\
黄茶 & Yellow Tea \\
玫瑰茶 & Rose Tea \\
紫笋茶 & Purple Bamboo Shoot Tea \\
普洱茶 & Pu'er Tea \\
雨前茶 & Pre-Grain Rain Tea \\
黄山毛峰 & Huangshan Maofeng Tea \\
\hline
\end{tabular}

\subsection{Tea Terminology with Specific Cultural Connotation}

A remarkable feature of Chinese tea terminology is that it has absorbed splendid Chinese culture. Chinese tea culture and Chinese traditional culture have already merged into an inseparable whole (He, 2016). In China, some tea terms are rich in connotative meaning and some of them are related to mythological stories or folklore. For this kind of translation of tea terminology with specific cultural connotation, the translator should not follow the ethics of representation and pursue faithfulness blindly. Instead, he should abandon the expression forms of the source language and directly translate the cultural connotation of tea terminology. This translation processing method will not cause the reader's reading burden, nor will it affect the overseas spread of Chinese tea culture due to the meaning loss of the source language. Translators should follow the communication ethics when translating such type of tea terminology. He can adopt the translation strategy of adding annotations or free translations, and try his best to make the target readers understand the meaning of the original tea terminology, so as to realize the cross-cultural communication between the source culture and the target culture. The following is an analysis of the guiding significance of communication ethics for the English translation of tea terminology with specific cultural images. Examples will be given from adding annotation and free translation respectively.

In Table 2, the name of “Old Man's Eyebrows Tea" was first mentioned by Grandmother Jia in the Dream of the Red Mansions, which refers to the white tip silver needle tea produced by Junshan Mountain of Dongting Lake, Hunan Province. Because of its shape as a long eyebrow, it is named "Old Man's Eyebrows Tea" (Cao, 1985). Therefore, it is necessary for the translator to add annotations to explain the name of the tea during the translation process so that the reader can achieve a good understanding. Similarly, the translation of "Sparrow Tongue Tea" needs to be annotated to explain the origin of the name of the tea, that is, the tea is shaped like a tongue, hence the name. If no annotations are added, readers will be mistaken for tea made by the sparrow tongue, and the consequences will be unimaginable. Another example is "Thunder Rolling Tea". If the translator does not add the annotation "which is harvested on 
Table 2. Examples of annotated translation of tea terminology guided by communication ethics.

\begin{tabular}{c}
\hline $\begin{array}{l}\text { Old Man's Eyebrows Tea (which refers to “White Tip Silver Needle Tea” } \\
\text { produced in Junshan Mountain of Dongting Lake, Hunan Province, because the } \\
\text { shape of tea is like long eyebrows, so it is named “Old Man's Eyebrows Tea”.) }\end{array}$ \\
$\begin{array}{c}\text { 雀舌茶 } \\
\text { Sparrow Tongue Tea (which is named after its shape.) } \\
\text { (蒙顶)雷鸣茶 }\end{array} \begin{array}{c}\text { Thunder Rolling Tea (which grows on the top of Mengding Mountain and is } \\
\text { harvested on the first rolling of the spring thunder.) }\end{array}$ \\
文君绿茶 $\quad$ Wenjun Green Tea (Wenjun is a talented female in ancient China.)
\end{tabular}

the first rolling of the spring thunder" to explain the origin of "Thunder Rolling Tea", it will make readers have a misunderstanding about the relationship between "thunder" and "tea" (Zhao, 2014).

In Table 3, “云腉” refers to white and plump tea leaves. If transliterated it as "yunyu" or literally translated as "fat cloud", the cultural meaning of this tea terminology is lost in Chinese, so it is best to translate it as "white buds" (Zhao, 2014). The tea terminology “杀青” refers to the use of high temperature to destroy the activity of oxidase in fresh tea leaves. According to this process, the translator can find the equivalent term in the target language, namely "enzyme-inhibit”. Another example, “茶质”, if literally translated as “the quality of tea”, it misinterprets the essence of the term, “茶质” refers to “the richness of tea in the taste", so it can be translated into "richness of tea flavor" by free translation strategy. The last terminology is “舌底鸣泉”, which means “tea will slowly produce saliva at the bottom of the tongue, just as there are many tiny bubbles coming together". This term is mainly intended to express the highest level of saliva production when drinking tea. If it is literally translated as "like sounding spring under his/her tongue", the readers may misinterpret the tea as tasting like spring water and will not be associated with "promoting the secretion of saliva" (Liang, 2018). Therefore, it is suggested that the translator should adopt the strategy of free translation and translate it into "produce saliva constantly in the base of tongue", which not only retains the cultural connotation of the original term, but also achieves the effect of cross-cultural communication.

Table 3. Examples of free translation of tea terminology guided by communication ethics.

$\begin{array}{lc}\text { 云腫 } & \text { white buds } \\ \text { 杀青 } & \text { enzyme-inhibit } \\ \text { 茶质 } & \text { richness of tea flavor }\end{array}$

舌底鸣泉 produce saliva constantly in the base of tongue

\subsection{Tea Terminology with Different Meanings in Chinese and Western Culture}

Many tea terms have deep cultural connotations in China, but if they are literally translated into foreign countries, in many cases, translations will not only fail to 
achieve the effect of communication, but also cause ambiguity. The cultures of the world are diverse. What is considered a mascot in one country may become a symbol of evil in another; what is highly respected in one country may be disliked by everyone in another country, so the culture differences between countries have brought many communication barriers (Yang, 2017). Therefore, for such tea terminology with international ambiguity, translators should follow the ethics of commitment in translation, fully consider the differences between Chinese and Western religious beliefs, cultural taboos, laws and regulations, and try to use the faithful and fluent translation to eliminate the confusion of Western readers.

For example, "Dragon" is a symbol of dignity and power in China, but in the West is a symbol of evil and disaster. Therefore, if “龙井茶(Longjing Tea)” is literally translated as "Dragon Well Tea", it is not only unfavorable to the understanding, but also very likely to trigger the antipathy of the target readers. In addition, the origin of the name of “龙井茶(Longjing Tea)" has nothing to do with "Dragon" and "well". "Longjing" is the name of a mountain village on the edge of the West Lake, since the main crop in this village was tea trees, thus the tea produced in this village is called "Longjing tea" (Xu, 2016). According to the above analysis, the translator can translate “龙井茶” into “Longjing Tea” by literal translation, which not only reflects the tea's characteristics, but also is conducive to the external communication of Chinese tea culture. Another example is the “大红袍(Dahongpao Tea)", which, if translated literally as "Big Red Robe", not only cannot reflect the characteristics of this tea, but also will cause misunderstanding among Western readers, because the word "red" in Chinese culture is more often a symbol of positive meanings such as happiness, luck and success, while in Western culture, "red" focuses more on cruelty, danger, violence and other negative meaning. Therefore, as a messenger of cultural communication, the translator has the responsibility to translate it accurately, which can be translated as "Dahongpao Tea". This translation not only reflects the respect for the cultural customs of foreign readers, but also retains the profound connotation of Chinese tea culture.

\subsection{Tea Terminology Used for Different Levels of Target Readers}

Translation of tea terms vary according to different target readers. Tea terms are frequently used by overseas students in China, students of Confucius Institutes, foreign friends who like tea, foreign tea enterprises, international tea forums, etc. Therefore, for different levels of target readers, translator should follow the principle of service ethics, actively understand the target reader's Chinese and tea culture knowledge level before translation, and also discuss translation requirements with customers, so as to provide more targeted translations.

In Table 4, the Chinese character “六安瓜片” refers to tea shaped like melon seeds produced in Lu'an City, Anhui Province. For target readers with higher Chinese level, translator can directly translate it into "Lu'an tea", because in China, "Lu'an Tea" generally refers to "Lu'an Melon Seeds Tea", while for target 
Table 4. Translation of tea terminology guided by the ethics of service.

\begin{tabular}{ccc}
\hline & $\begin{array}{c}\text { For target readers without Chinese and For the target readers with higher Chinese } \\
\text { and tea culture foundation }\end{array}$ \\
\hline 六安瓜片 & Lu'an Melon Seeds Tea & Lu'an Tea \\
女儿茶 & Herbal tea-wutong-tips & Nuer Tea \\
碧螺春 & Green Snail Spring & Biluochun Tea \\
铁观音 & Tea Buddha & Tieguanyin Tea \\
\hline
\end{tabular}

readers have little knowledge of China, the translator needs to adopt free translation strategy and translate it into "Lu'an Melon Seeds Tea", by describing the shape of tea, enables readers to have a better understanding of the tea.

Another example is “女儿茶”, which is not real tea, but the leaves of phoenix tree collected from Tianshan Mountains (Yang \& Yang, 1994). During the translation process, translators can directly transliterate it into "Nuer Tea" to target readers who are familiar with Chinese tea culture, while for target readers who have no basis in tea culture, the translator needs to translate it as "Herbal tea-wutong-tips (wutong refers to the phoenix tree)" (Hawkes, 1973), which makes it easier for readers to understand the nature and characteristics of the tea.

Similarly, “碧螺春” originally translated as “ tea with appalling fragrance” for its strong aroma. Later, Emperor Kangxi thought that "appalling fragrance" was too vulgar. He noticed the tea leaves were green and curly, so give the name "Biluochun" (green snail spring) (Wu, 2018). The tea has long been famous both at home and abroad, so the translator can directly transliterate it into "Biluochun Tea" for readers who are familiar with Chinese tea culture, and "Green Snail Spring" for readers without tea culture foundation.

“铁观音” is the same as above, which is usually translated as "Tieguanyin Tea". However, if the translator serves the readers without the foundation of tea culture, it can be translated as "Tea Buddha", which not only retains the Buddhist cultural elements, but also facilitates the understanding of Western readers.

\subsection{Tea Terminology Widely Accepted in the West}

In the long history of Chinese tea culture spreading abroad, many Chinese and foreign scholars have successfully translated a lot of tea culture terms and classics. Therefore, many tea terms have been widely accepted by overseas readers, especially the ten famous Chinese teas such as “龙井茶(Longjing Tea)”, “碧螺春 (Biluochun Tea)”, “铁观音(Tieguanyin Tea)”, “黄山毛峰茶(Huangshan Maofeng Tea)" and so on. These tea brands not only have an important position in the mind of Chinese people, but also have a great influence in the international market. Therefore, for the translation of famous tea and other tea terms that are well accepted in the West, the translator should follow the norm-based ethics, be faithful to the cultural norms of the target language, be faithful to the target readers, fully respect the choices of the target readers and the target language society, and translate such terms directly into the widely accepted translation of 
Table 5. Translation of tea terminology guided by the norm-based ethics.

\begin{tabular}{cc}
\hline Tea terminology widely accepted in the west & $\begin{array}{c}\text { Tea terminology translation guided by the } \\
\text { norm-based ethics }\end{array}$ \\
\hline 西湖龙井 & West Lake Longjing Tea \\
碧螺春 & Biluochun Tea \\
铁观音 & Tieguanyin Tea \\
君山银针 & Junshan Yinzhen Tea \\
大红袍 & Dahongpao Tea \\
太平猴魁 & Taiping Houkui Tea \\
\hline
\end{tabular}

the target culture without having to choose another translation. As shown in Table 5.

\section{Conclusion}

Finding appropriate ways to represent the original meaning of the source text in the target text based on comprehension is the precondition to ensure the quality of the translation. But the processes of comprehension and representation are constrained by the translation ethics, especially, to the translation of tea terminology.

This paper first reviewed Chesterman's five models of translation ethics, namely the ethics of representation, ethics of service, ethics of communication, norm-based ethics and ethics of commitment. Then, the relationship between Chesterman's five models and tea terminology translation was discussed in combination with the internal characteristics and external constraints of tea terminology. On this basis, the application of the five models in the translation of five different types of tea terminology was analyzed. It was found that Chesterman's five models are applicable in the translation of different types of tea terms. The result will provide a reference in the improvement of tea terminology translation quality.

\section{Conflicts of Interest}

The authors declare no conflicts of interest regarding the publication of this paper.

\section{References}

Cao, X. Q. (1985). A Dream of Red Mansions. Beijing: People's Literature Publishing House.

Chen, Z. D. (2010). Translation Ethics: Chesterman's Five Ethical Models. Foreign Theoretical Trends, 3, 85-88.

Chesterman, A. (2001). Proposal for a Hieronymic Oath. The Translator, 2, 139-154. https://doi.org/10.1080/13556509.2001.10799097

Deng, F. (2018). Strategies and Causes of English Translation of Tea Vocabulary. Tea in Fujian, 3, 342. 
Hawkes, D. (1973). The Story of the Stone (p. 219). London: Penguin Books.

He, J. (2016). On English Translation of Tea Terminology. Tea in Fujian, 10, 262-263.

Heng, Q. Z. (2017). Application of Discourse Analysis in the Tea Terminology Translation. Tea in Fujian, 10, 263-264.

Hu, L. L. (2012). On Lu Xun's Hard Translation from Translation Ethics. Journal of University of Science and Technology Beijing (Social Sciences Edition), 3, 10-15.

Li, H. (2019). English Translation of Chinese Idioms from the Perspective of Translation Ethics. Journal of Heilongjiang College of Education, 3, 123-125.

Li, W. L. (2016). Study on the Problems and Countermeasures of Tea Names Publicity Translation in the Perspective of Skopos Theory. Tea in Fujian, 9, 351-352.

Liang, T. Z. (2018). Study on the Translation of Tea Culture Terminology from the Perspective of Applied Linguistics. Tea in Fujian, 3, 423.

Luo, H. (2014). On Contributions and Limitations of Chesterman's Translation Ethics Model. Journal of Guiyang University (Social Science), 6, 61-63.

Peng, P. (2013). Translation Ethics (p. 149). Beijing: Central Compilation \& and Translation Press.

Pym, A. (2012). On Translator Ethics (p. 9). Amsterdam/Philadelphia: John Benjamins. https://doi.org/10.1075/btl.104

Wu, X. L. (2018). Illustrated Chinese Tea Stories (p. 111). Beijing: China Agriculture Press.

Xu, X. S. (2016). Analysis on Translation Problems of Tea Culture Terminology in Tea Export Trade. Tea in Fujian, 4, 36-37.

Yang, P. (2017). Translation of Tea Trademarks in Cross-Cultural Advertising Dissemination. Tea in Fujian, 1, 292-293.

Yang, X. Y., \& Yang, G. (1994). A Dream of Red Mansions (p. 1909). Beijing: Foreign Languages Press.

Ye, H. (2017). Analysis of Chinese Tea Export Translation. Tea in Fujian, 2, 51-52.

Zhao, X. Q. (2014). Exploring the Skills of Translating Chinese Tea Culture: A Report on the Translation Project of A Sip of Chinese Tea (Extract). MA Thesis, Liaoning: Shenyang Normal University.

Zhu, Z. Y. (2009). Translation Studies: Prescription, Description, and Ethics. Chinese Translators Journal, 3, 5-12+95. 